
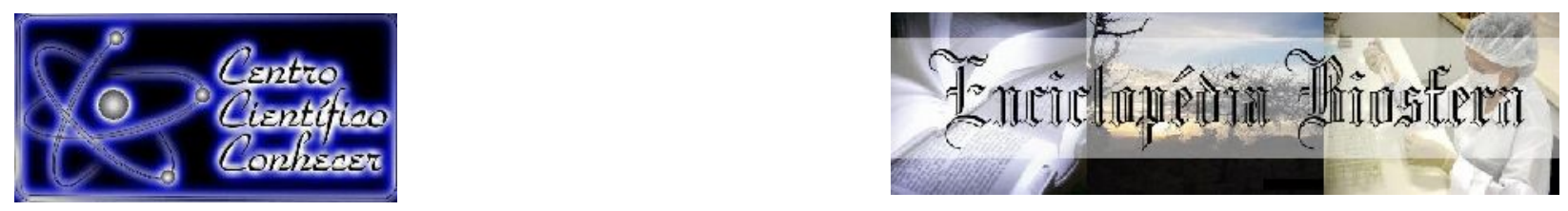

\title{
AVALIAÇÃO DO FRESCOR E PESQUISA DE SULFITOS EM CARNES PRÉ-MOÍDAS E ALMÔNDEGAS COMERCIALIZADAS EM ESTABELECIMENTOS VAREJISTAS DE UBERLÂNDIA, MINAS GERAIS, BRASIL
}

Tainara Pereira da Silva ${ }^{1}$, Larissa Mendonça Vieira1', Igor Carrijo Fernandes de Araújo ${ }^{1}$, Kênia de Fátima Carrijo ${ }^{2}$

1 Médicos Veterinários graduados pela Universidade Federal de Uberlândia Uberlândia-MG, Brasil.

2 Professora Doutora da Universidade Federal de Uberlândia

(keniafcarrijo@yahoo.com.br)

Recebido em: 06/04/2019 - Aprovado em: 10/06/2019 - Publicado em: 30/06/2019

DOI: 10.18677/EnciBio_2019A26

\begin{abstract}
RESUMO
A carne moída possui grande aceitação e popularidade no mercado por associar baixo custo a uma versatilidade de preparos. O processo de moagem e manipulação aceleram sua deterioração. Devido à perecebilidade, comerciantes podem recorrer a artifícios fraudulentos para a redução de perdas, como o acréscimo de aditivos alimentares, expressamente proibidos pela legislação para carnes frescas, destacando-se dentre estes, o sulfito de sódio. A adição deste aditivo pode causar agravos à saúde do consumidor. Este trabalho objetivou avaliar o frescor e pesquisar sulfitos em carnes pré-moídas e almôndegas comercializadas em estabelecimentos varejistas de Uberlândia-MG. Foram analisadas 40 amostras de almôndega e cinco de carne pré-moída de oito estabelecimentos de cada uma das cinco regiões do município. Para avaliar o frescor, o $\mathrm{pH}$ foi mensurado pelo método descrito no Manual do Instituto Adolfo Lutz e pelo descrito na Instrução Normativa n-20/1999 do Ministério da Agricultura e todas as amostras foram consideradas boas para o consumo. Na prova de filtração, realizada nas amostras de carne pré-moída, o tempo de filtração foi menor ou iguais a cinco minutos, sendo consideradas boas para consumo. As amostras de carnes bovina pré-moídas, submetidas à prova de cocção, apresentaram odor característico de carne in natura. A pesquisa de sulfito apresentou resultados negativos para todas as amostras de carne pré-moída enquanto que $15 \%$ das 40 amostras de almôndega foram positivas. Constatou-se que existem estabelecimentos em Uberlândia-MG que adicionam sulfito de sódio em almôndegas.
\end{abstract}

PALAVRAS-CHAVE: Aditivos Alimentares, carne bovina, fraudes em alimentos. 


\title{
EVALUATION OF FRESHNESS AND SULPHITE RESEARCH IN PRE-MOIST MEATS AND MEATBALLS MARKETED IN RETAILER ESTABLISHMENTS OF UBERLÂNDIA, MINAS GERAIS, BRAZIL
}

\begin{abstract}
The ground beef has great acceptance and popularity in the market by associating low cost with a versatility of preparation. Its milling and handling process accelerates its deterioration. Due to their perishability, traders can resort to fraudulent devices to reduce losses, such as the addition of food additives, which are expressly prohibited by the legislation for fresh meat, especially sodium sulphite. The addition of this additive can cause harm to the health of the consumer. The objective of this work was to evaluate the freshness and to investigate sulfites in pre-ground meats and meatballs commercialized in retail establishments of Uberlândia-MG, Brazil. 40 samples of meatballs and 5 samples of pre-ground beef from eight establishments in each of the five regions of the municipality were analyzed. To evaluate the freshness, the $\mathrm{pH}$ was measured by the method described in the Adolfo Lutz Institute Manual and that described in Normative Instruction No. 20/1999 of the Ministry of Agriculture and all samples were considered good for consumption. In the filtration test, carried out on the samples of pre-ground beef, the filtration time was less than or equal to 5 minutes and considered good for consumption. The samples of pre-ground bovine meat, submitted to the cooking test, showed characteristic odor of meat in natura. The sulphite test showed negative results for all pre-ground beef samples while $15 \%$ of the 40 meatballs samples were positive. It was verified that there are establishments in Uberlândia-MG, Brazil that add sodium sulphite in meatballs.
\end{abstract}

KEYWORDS: Food additives, food fraud, beef

\section{INTRODUÇÃO}

A carne bovina é considerada um alimento de alto valor biológico, por ser uma fonte rica de proteínas, fornecendo aminoácidos essenciais. Também apresenta ácidos graxos essenciais, teores significativos de vitaminas do complexo $\mathrm{B}$ e minerais, dentre estes o zinco e o ferro em uma forma altamente biodisponível (BRIDI, 2014).

A carne moída é um derivado de destaque, resultante da moagem de cortes de carne bovina. Possui alta aceitação e popularidade no mercado devido à sua versatilidade de preparos. Segundo a Instrução Normativa 83, de 21 de novembro de 2003, do Ministério da Agricultura, Pecuária e Abastecimento - MAPA (BRASIL, 2003), entende-se por Carne Moída de bovino o produto cárneo obtido a partir da moagem de massas musculares de carcaças de bovinos, seguido de imediato resfriamento ou congelamento, com teor máximo de $15 \%$ de gordura.

A partir da carne moída, outros derivados cárneos podem ser preparados, como por exemplo, as almôndegas, que de acordo com a Instrução Normativa 20, de 31 de julho de 2000 (BRASIL, 2000) do MAPA, é o produto cárneo industrializado, obtido a partir da carne moída de uma ou mais espécies de animais de açougue, moldada na forma arredondada, adicionada de ingredientes e submetido a processo tecnológico adequado.

A carne moída manifesta um maior potencial de deterioração que a carne na forma de cortes, devido à sua procedência, muitas vezes de retalhos de carnes e por seu processamento incluir intensa manipulação. Outros fatores como características nutricionais, $\mathrm{pH}$ próximo à neutralidade e maior atividade de água tornam a carne um meio de cultura favorável ao crescimento de microrganismos (NASCIMENTO et al., 2014; OLIVEIRA et al., 2017). 
Para mascarar a perda de qualidade da carne e até um possível estado de putrefação incipiente, alguns comerciantes fazem uso da adição de aditivos conservantes ao produto, prática facilitada quando a carne não é moída na frente do consumidor, sendo um desses aditivos, o sulfito de sódio (FERNANDES et al., 2014). Tal prática é proibida segundo a Portaria no 540 de 27 de outubro de 1997 (BRASIL, 1997) da Agência Nacional de Vigilância Sanitária (ANVISA) por mascarar alteração ou adulteração da matéria-prima ou do produto já elaborado e induzir o consumidor a erro, engano ou confusão. A Portaria nำ 1004, de 11 de dezembro de 1998 (BRASIL, 1998) da ANVISA contêm a Atribuição de Função de Aditivos, Aditivos e seus Limites Máximos de uso para a Categoria 8 - Carne e Produtos Cárneos, não sendo permitido o uso de qualquer aditivo em carnes frescas.

Os sulfitos são classificados como aditivos alimentares e tem propriedades que impedem as reações de escurecimento enzimático e não enzimático. Consequentemente proporciona à carne bovina aparência fresca, com coloração vermelha e minimização do odor de deterioração (FELLOWS, 2018). A ingestão de sulfitos tem sido associada a reações adversas, especialmente, em indivíduos asmáticos. As reações mais comuns registradas são crises asmáticas, urticária, anafilaxia, hipotensão, náuseas e diarreia (VALLY et al., 2009; BAN et al., 2014; GOUVEIA et al., 2016; KENDIGELEN et al., 2016).

Assim, por ser considerada uma ação fraudulenta a adição deste aditivo em carnes in natura e em almôndegas, associado ao fato de sua presença trazer sérios agravos à saúde do consumidor, é de fundamental importância que seja pesquisada a presença deste aditivo nestes alimentos.

Diante do exposto, o objetivo do presente trabalho foi pesquisar a presença de sulfitos em carnes pré-moídas in natura e em almôndegas comercializadas em estabelecimentos varejistas de Uberlândia, Minas Gerais, a fim de verificar se as mesmas estão de acordo com o preconizado pela legislação, avaliando ainda características indicativas de frescor em carnes pré-moídas (odor, por meio da prova de cocção, deterioração proteica, por meio da prova de filtração e $\mathrm{pH}$, por meio da comparação de duas metodologias).

\section{Amostragem}

\section{MATERIAL E MÉTODOS}

Foram utilizadas 40 amostras de almôndega de carne bovina e cinco amostras de carne bovina pré-moída para a realização da presente pesquisa. As amostras foram adquiridas, na condição de consumidor, em açougues e supermercados localizados nas cinco regiões do município de Uberlândia - MG.

Para determinar a área de coleta das amostras foi consultado o mapa base da cidade, disponível no site da Prefeitura Municipal de Uberlândia (http://www.uberlandia.mg.gov.br), que divide o município em cinco regiões, sendo: norte, sul, leste, oeste e centro. Em cada região foram amostrados oito bairros de forma aleatória, que tiveram os estabelecimentos comercias (açougues, supermercados e mercearias que comercializam carnes) listados. A partir dessa etapa foi sorteado um estabelecimento de cada bairro para aquisição da amostra. Para os sorteios, foi utilizada a plataforma: https://www.random.org.

Cada amostra adquirida, na condição de consumidor, tanto de carne prémoída quanto de almôndega, apresentava peso equivalente a 200 gramas e, após a aquisição no comércio, estas foram acondicionadas em caixa térmica com gelo reciclável e imediatamente levadas para serem analisadas no Laboratório de Tecnologia e Inspeção de Produtos de Origem Animal da Faculdade de Medicina 
Veterinária da Universidade Federal de Uberlândia (UFU).

\section{Análise de pH}

Para a avaliação do frescor, foi realizada a mensuração do pH utilizando-se dois métodos, visando comparar as metodologias. O primeiro método foi baseado na Instrução Normativa 20, de 21 de julho de 1999 (BRASIL, 1999), do MAPA, que oficializa os Métodos Analíticos Físico-Químicos para Controle de Produtos Cárneos e seus ingredientes - Sal e Salmoura, sendo portanto a metodologia oficial a ser utilizada nos laboratórios de referência agropecuários. Para isso foram pesadas 50 gramas da amostra a ser analisada, sendo a seguir, homogeneizadas com $20 \mathrm{~mL}$ de água destilada fervida e recentemente resfriada. A seguir, o potenciômetro de um pHmetro previamente aferido, foi introduzido na mistura. A leitura direta foi feita no visor do aparelho cinco minutos depois. Esta análise foi realizada em triplicata para cada amostra.

O segundo método foi baseado no Manual do Instituto Adolfo Lutz (IAL, 2008). Para isso, 10 gramas da amostra, previamente pesados, foram homogeneizados com $100 \mathrm{~mL}$ de água destilada e o potênciometro, de um pHmetro previamente aferido, foi introduzido na mistura. A leitura direta foi feita no visor do aparelho cinco minutos depois. Esta análise também foi realizada em triplicata para cada amostra. Os dados obtidos foram registrados em planilha e obtidas as médias. Em posse dos valores médios de $\mathrm{pH}$, estes foram comparados com os valores da Portaria $\mathrm{n}^{\circ}$ 1, de 7 de outubro de 1981 (BRASIL, 1981) que regulamenta os métodos analíticos para controle de produtos de origem animal e seus ingredientes, e apresenta valores de $\mathrm{pH}$ das carnes entre: 5,8 e 6,2, o que indica carne boa para consumo; 6,4 que indica que carne para consumo imediato e acima de 6,4 que se classifica como início de decomposição.

\section{Prova da filtração}

Para a realização da prova da filtração, adotou-se a metodologia descrita na IN 20/1999 - MAPA (BRASIL, 1999), que foi realizada com a finalidade de verificar o tempo necessário para a passagem do extrato aquoso da carne por um papel de filtro padronizado, que esta associado com o grau de deterioração proteica. Nesta prova, 10 gramas da amostra, previamente pesados, foram colocados em Erlenmeyer com rolha esmerilhada e a seguir adicionados $100 \mathrm{~mL}$ de água destilada. Após agitação vigorosa por 15 minutos, com intervalos de repouso, a mistura foi filtrada em funil com papel de filtro Whatman $n^{\circ} 1$, cronometrando-se 0 tempo.

Os produtos solúveis da decomposição de proteínas condicionam lentidão na filtração. Nesse sentido, quanto maior o tempo para que ocorra a filtração, mais deteriorada encontra-se a carne. Assim, a qualidade da carne, baseada no tempo necessário para a filtração, está descrita a seguir:

- 5 minutos: carne fresca e sã, boa para consumo;

- 6-10 minutos: carne de média conservação;

- 10 minutos ou mais: carne suspeita, provavelmente alterada.

O filtrado da carne sã apresenta-se límpido, róseo claro, com cheiro sui generis e reação ácida. Já a carne alterada apresenta filtrado turvo, de tonalidade groselha, reação alcalina e odor amoniacal. Esta prova foi aplicada apenas para a carne pré-moída. 


\section{Análise de Sulfito de Sódio}

Para análise da presença de sulfito de sódio foi utilizada a Prova para sulfito com verde de malaquita, determinada pelo Instituto Adolfo Lutz (IAL, 2008) que baseia-se na mudança de cor do corante orgânico verde de malaquita na presença de anidrido sulfuroso e de sulfitos. Foram acrescentados meio $\mathrm{mL}$ da solução de verde malaquita $0,02 \% \mathrm{~m} / \mathrm{v}$ a três gramas e meio da amostra em cápsula de porcelana. A amostra foi misturada com o auxílio de espátula por dois minutos. Esta prova foi realizada em triplicata.

O resultado da ánalise foi obtido através da observação da cor da amostra após o procedimento. Segundo Instituto Adolfo Lutz (IAL, 2008) a presença de sulfito descora a solução de verde malaquita e, na ausência de sulfito, a amostra adquire coloração azulada.

\section{Prova de cocção}

Para a realizar a prova de cocção 20 gramas de carne pré moída foram colocados em um béquer e cobertos com água destilada. O béquer foi tampado com vidro de relógio e a mistura foi aquecida até o início dos primeiros vapores com finalidade de analisar o odor da amostra. Foi realizada então a descrição dos odores exalados. Esta prova foi aplicada apenas para a carne pré-moída (BRASIL, 1999).

\section{Análise dos dados}

Após a obtenção dos dados, estes foram digitados para uma planilha do Excell, agrupando os resultados das amostras, de acordo com cada região da cidade. A análise estatística foi realizada com o auxílio do pacote de dados do software "R". Foi realizada a análise de variância (ANOVA) das médias de $\mathrm{pH}$ obtidas após a análise das amostras obtidas nas diferentes regiões e a seguir, aplicado o Teste de Tukey, para verificar se as médias diferiam entre si.

Adicionalmente, foi realizada a ANOVA entre as médias de $\mathrm{pH}$, independente da região de procedência das amostras, relativos aos dois métodos utilizados e a seguir, foi feita a comparação das médias por meio do Teste de Tukey, a fim de comparar as médias entre si. A seguir, foram plotados os "box plots" das médias obtidas. O intervalo de confiança adotado foi de $95 \%$.

\section{Análise de $\mathrm{pH}$}

\section{RESULTADOS E DISCUSSÃO}

A mensuração do $\mathrm{pH}$ visa determinar as condições ácidas ou básicas do meio através da concentração de íons de hidrogênio. É uma medida importante, pois o pH influencia em vários aspectos da carne, entre eles a cor, a capacidade de retenção de água, a textura e a palatabilidade (HOPKINS;FOGARTY, 1998 citados por CRUZ et al., 2015). A média dos valores de pH das amostras de almôndega, obtida pela metodologia do Instituto Adolfo Lutz, apresentou variação entre 5,61 e 6,53 (Figura 1). Os dois extremos foram obtidos em amostras coletadas na Região Leste. A metodologia descrita pela Instrução Normativa 20/1999 do MAPA (BRASIL, 1999) apresentou valores médios de $\mathrm{pH}$ variando de 5,43 à 6,09 , sendo o valor mais baixo obtido na Região Leste e o mais alto na Região Norte (Figura 2). Seguindo o padrão que classifica carnes com pH entre 6,0 e 6,4 como boas para consumo; apenas uma amostra de almôndega apresentou valor acima do considerado aceitável na primeira metodologia usada, enquanto que utilizando metodologia baseada na Instrução Normativa 20, de 21 de julho de 1999, todas as amostras de almôndega apresentaram valores adequados ao consumo humano. 


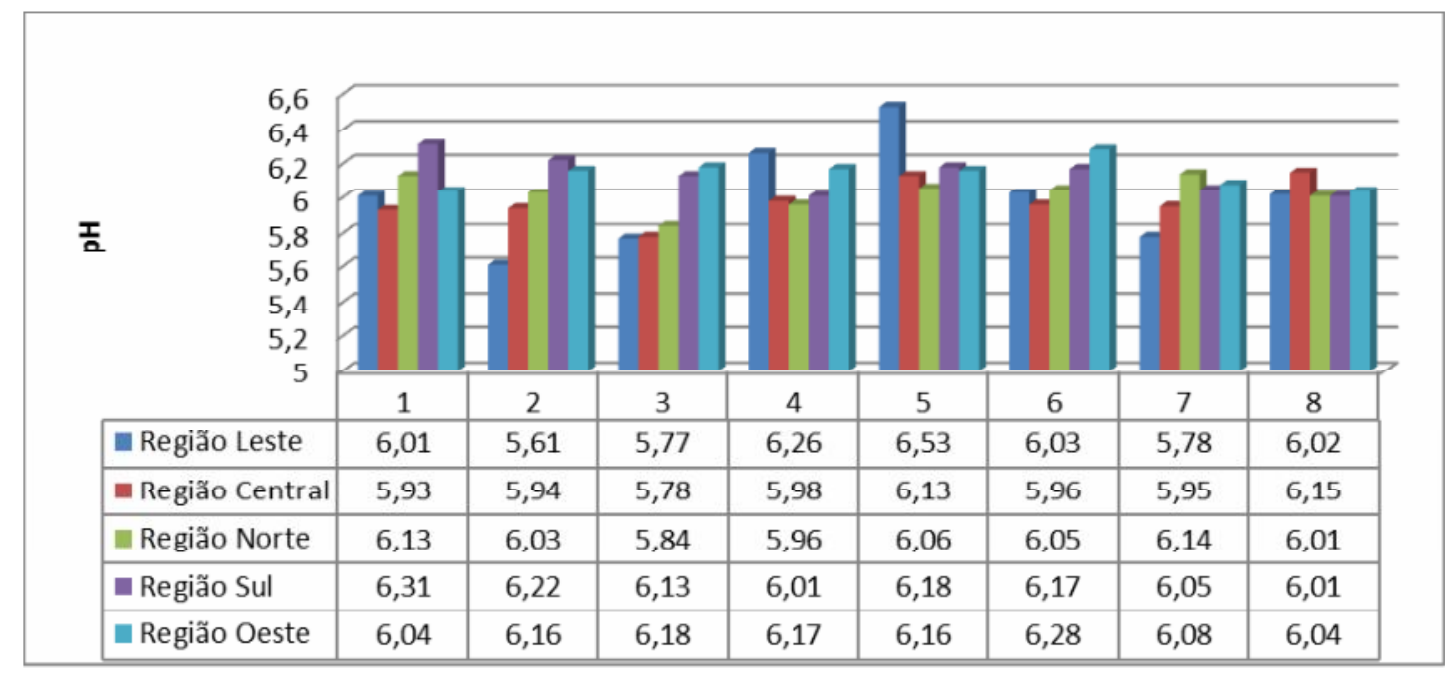

FIGURA 1. Médias de pH de almôndegas, adquiridas em estabelecimentos varejistas nas cinco regiões do município de Uberlândia - MG, obtidas por meio da metodologia do Instituto Adolfo Lutz. Amostras de cada região foram numeradas de 1 a 8 .

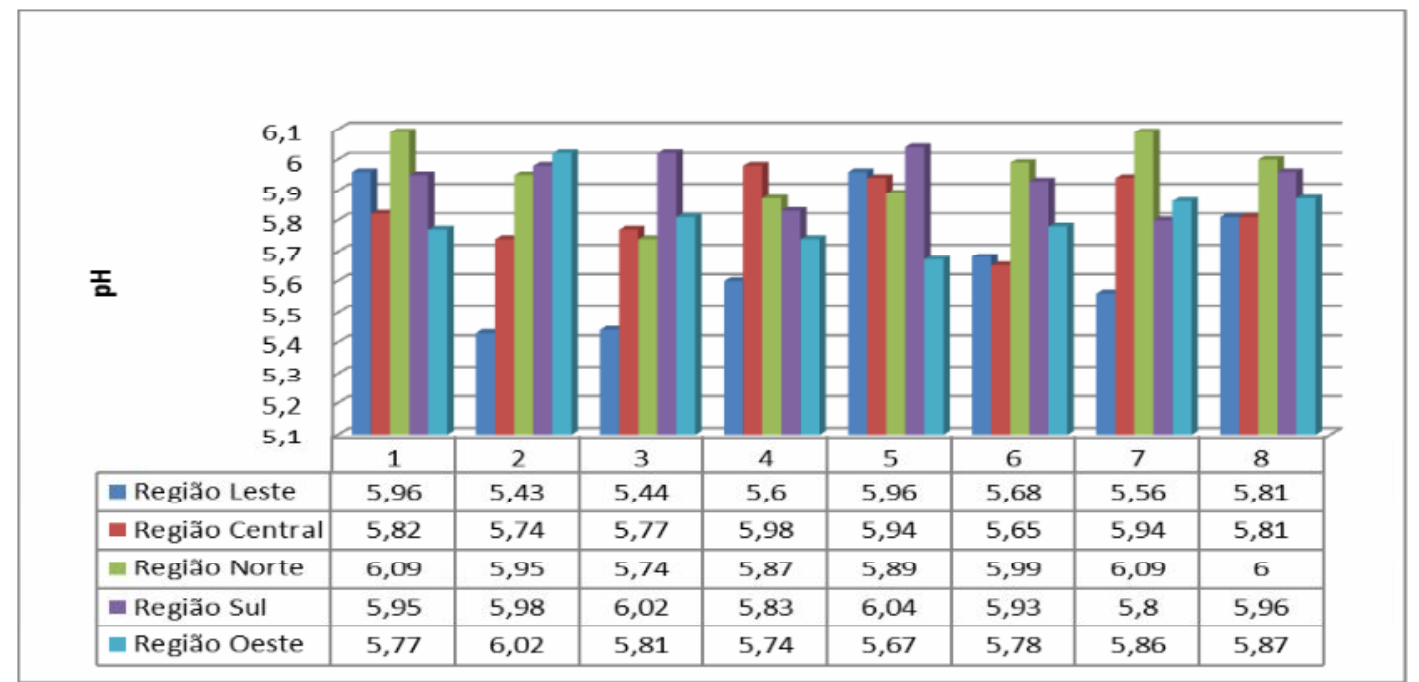

FIGURA 2. Médias de $\mathrm{pH}$ de almôndegas, adquiridas em estabelecimentos varejistas nas cinco regiões do município de Uberlândia - MG, obtidas por meio da metodologia descrita na Instrução Normativa 20, de 21 de julho de 1999 (BRASIL, 1999). As amostras de cada região foram numeradas de 1 a 8.

De acordo com a Portaria no 1, de 7 de outubro de 1981 (BRASIL, 1981) que regulamenta os métodos analíticos para controle de produtos de origem animal e seus ingredientes, o pH das carnes pode apresentar valores entre: 5,8 e 6,2, o que indica carne boa para consumo; 6,4 indica carne para consumo imediato e acima de 6,4 que se classifica como início de decomposição. De acordo com esse padrão, $10 \%$ das amostras de almôndega analisadas pelo método do Instituto Adolfo Lutz apresentaram valores de $\mathrm{pH}$ menores que 5,8; 87,5\% das amostras podem ser consideradas boas para consumo e 2,5\% das amostras consideradas boa para consumo imediato. As amostras analisadas pela metodologia descrita pela Instrução Normativa 20, de 21 de julho de 1999 (BRASIL, 1999), apresentaram 32,5\% das 
amostras com valores abaixo de 5,8 e 67,5\% das amostras de almôndega foram consideradas boas para consumo.

$\mathrm{Na}$ figura 3 estão representadas as médias de $\mathrm{pH}$ das amostras de almôndega mensuradas através da metodologia descrita pelo Instituto Adolfo Lutz; comparando os resultados obtidos em cada região. A amplitude interquartil (AIQ) apresentada pela região leste foi a mais elevada. Esse fato, associado aos limites inferior e superior distantes do centro mostram que as médias mensuradas nessa região sofreram maior variação se comparadas às outras regiões. Em contrapartida, a região oeste apresentou médias mais uniformes; fato que pode ser notado através da proximidade dos limites inferior e superior do centro do gráfico. Apenas a região norte apresentou simetria entre as médias de $\mathrm{pH}$ observadas. Nas demais regiões, as médias apresentaram-se assimétricas.

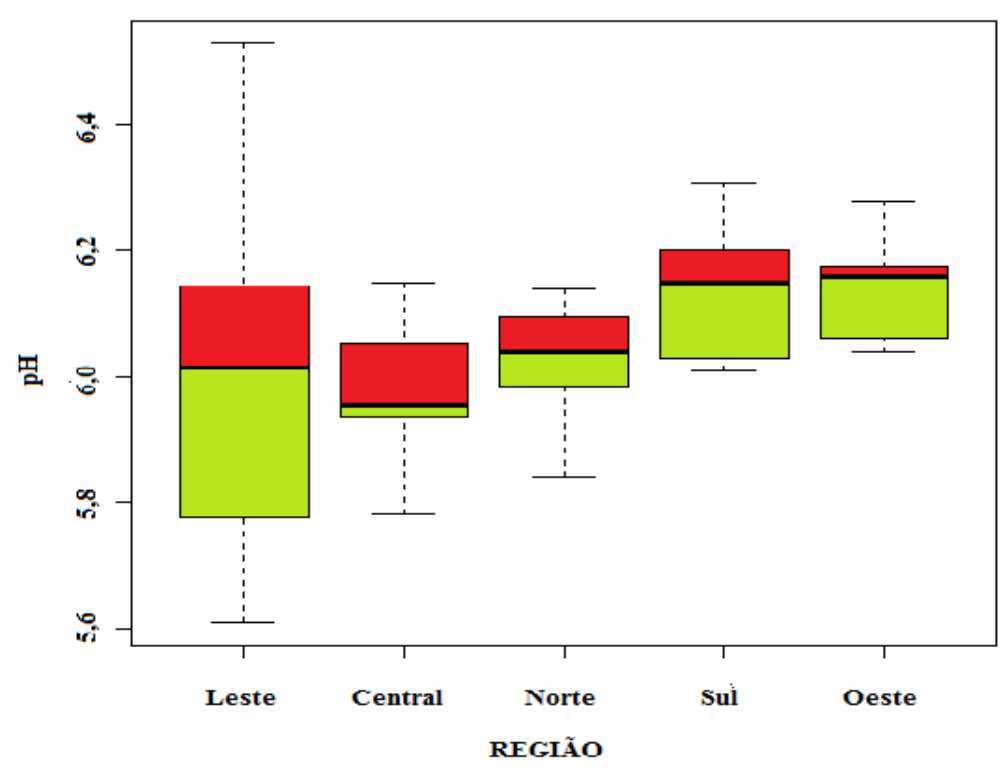

FIGURA 3. Comparação entre as médias de pH mensuradas a partir do método descrito pelo Instituto Adolfo Lutz.

Os resultados obtidos com a metodologia do Instituto Adolfo Lutz apresentamse concentrados, em sua maioria, em torno de valores próximos. Na tabela 1 estão apresentados os valores resultantes da aplicação do teste de ANOVA que comprovam essa situação; pelo teste $\mathrm{F}$ da análise de variância, conclui-se que não existem diferenças significativas entre as médias de $\mathrm{pH}$ das amostras de almôndega analisadas nas regiões estudadas.

TABELA 1. Resultados do Teste de ANOVA aplicado nos resultados obtidos com a metodologia para análise de $\mathrm{pH}$, do Instituto Adolfo Lutz.

\begin{tabular}{cccccc}
\hline FV & GL & SQ & QM & F & p-valor \\
\hline Região & 4 & 0,18448 & 0,046121 & 1,812 & 0,1486 \\
Erro & 35 & 0,025454 & 0,025454 & & \\
\hline Total & 39 & 0,209934 & & &
\end{tabular}


As médias de $\mathrm{pH}$ das amostras de almôndega mensuradas através da metodologia descrita pela Instrução Normativa 20, de 21 de julho de 1999 (BRASIL, 1999), foram divididas por região e comparadas através de "box plots" (Figura 4). Os resultados apresentam amplitude interquartil (AIQ) maiores do que as obtidas através do método do Instituto Adolfo Lutz, sendo a maior variação pertencente à região leste nesse caso também. Apesar de apresentar valores médios mais baixos, esse método possui valores máximos mais próximos da mediana, ou seja, os valores mais altos tendem a ser os mais comuns. As cinco regiões apresentam distribuição assimétrica do resultado.

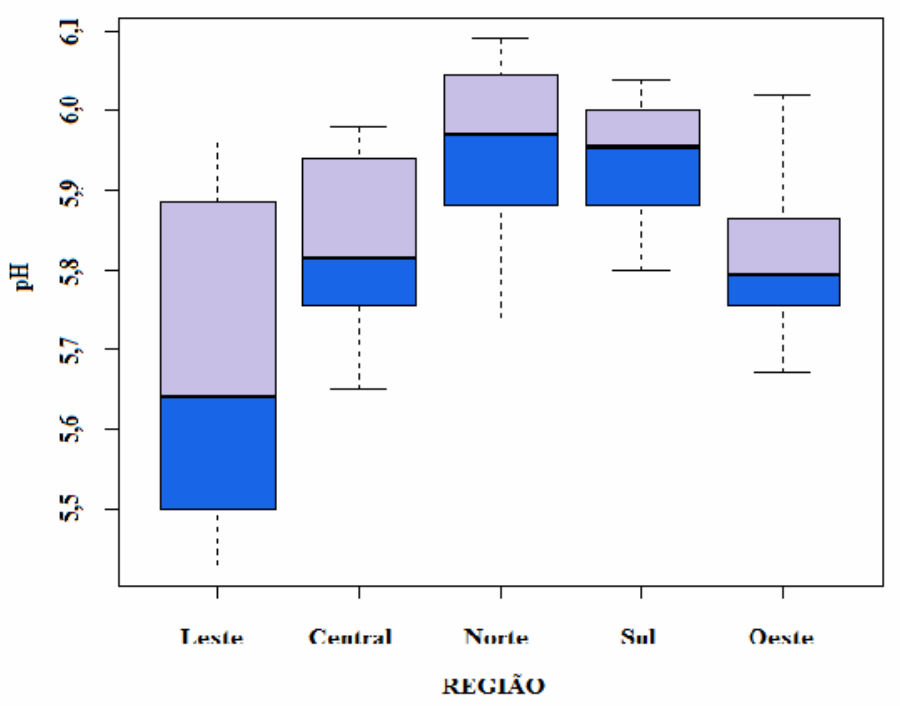

FIGURA 4. Comparação entre as médias de $\mathrm{pH}$ mensuradas a partir do método descrito pela Instrução Normativa 20, de 21 de julho de 1999 (BRASIL, 1999).

Os resultados apresentados pela análise de $\mathrm{pH}$ das amostras de almôndega, seguindo a metodologia da Instrução Normativa 20, de 21 de julho de 1999 (BRASIL, 1999), revelaram valores menos concentrados, se comparados aos resultados obtidos com a metodologia do Instituto Adolfo Lutz, ao redor da mediana. $O$ teste de ANOVA revelou que essa dispersão causou diferenças significativas $(\mathrm{p}<0,05)$ entre as médias de $\mathrm{pH}$ das amostras de almôndega das regiões avaliadas. $\mathrm{Na}$ tabela 2 estão representados os resultados do teste de ANOVA aplicado para as médias de pH mensuradas através da metologia da Instrução Normativa 20, de 21 de julho de 1999 (BRASIL, 1999).

TABELA 2. Resultados do Teste de ANOVA aplicado nos resultados obtidos com a metodologia descrita na Instrução Normativa 20, de 21 de julho de 1999 (BRASIL, 1999).

\begin{tabular}{cccccc}
\hline FV & GL & SQ & QM & F & p-valor \\
\hline Região & 4 & 0,38919 & 0,097296 & 5,4008 & 0,001705 \\
Erro & 35 & 0,63052 & 0,018015 & & \\
\hline Total & 39 & 1,01971 & & &
\end{tabular}


Por meio do Teste de Tukey, foram comparadas as médias de pH obtidas em cada região (tabela 3), indicando que as regiões norte e sul são estatisticamente iguais, porém diferem das regiões leste, oeste e central que, por sua vez, apresentam semelhança entre si. A maior diferença estatística foi encontrada nas comparações entre leste-norte e leste-sul.

TABELA 3 - Comparação das médias de pH, obtidas através da metodologia descrita pela IN 20/1999, por meio do Teste de Tukey*

\begin{tabular}{cc}
\hline Região & Médias \\
\hline Norte & 5,95 ba \\
Sul & 5,94 ba \\
Central & 5,83 a \\
Oeste & 5,82 a \\
Leste & 5,68 a \\
\hline
\end{tabular}

*Letras iguais representam médias estatisticamente iguais.

Price e Schwigert (1994) consideram carnes com pH entre 5,3 e 6,5 boas para consumo. Seguindo o padrão considerado por esses autores, os resultados obtidos no presente estudo, usando as duas metodologias citadas, mostram que todas as amostras de almôndega analisadas estão boas para o consumo.

A carne bovina pré-moída foi encontrada em apenas 5 estabelecimentos, sendo 4 da Região Leste e 1 da Região Central. $\mathrm{O}$ pH das amostras foi analisado utilizando a metodologia descrita no manual do Instituto Adolfo Lutz apresentou médias variando entre 5,49 e 6,35; já as amostras avaliadas pela metodologia descrita na Instrução Normativa 20, de 21 de julho de 1999 (BRASIL, 1999) obtiveram variação menor, apresentando resultados entre 5,5 e 5,88 . Na figura 5 estão apresentados os valores médio de $\mathrm{pH}$ das amostras de carne bovina prémoída que foram obtidos usando a metodologia do Instituto Adolfo Lutz e a metodologia descrita pela Instrução Normativa 20/1999 (BRASIL, 1999).

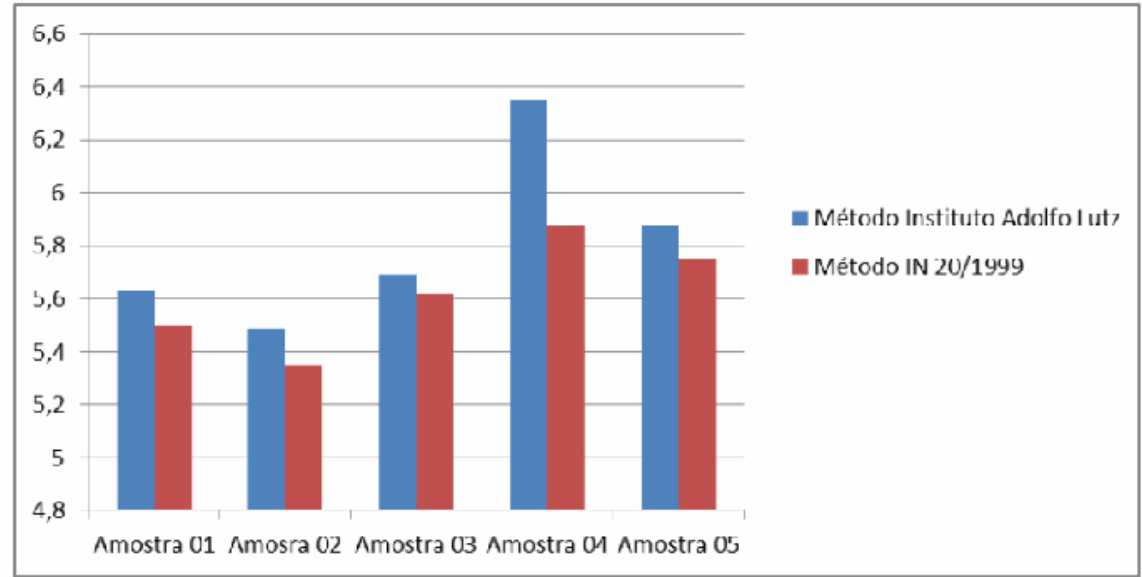

FIGURA 5. Médias do pH das amostras de carne bovina prémoída, adquiridas em estabelecimentos varejistas da região leste e central do município de Uberlândia - MG, obtidas por meio da metodologia do Instituto Adolfo Lutz e da metodologia pela Instrução Normativa 20, de 21 de julho de 1999 (BRASIL, 1999). 
$\mathrm{O}$ presente trabalho apresentou quantidade significativa de médias de $\mathrm{pH}$, tanto nas amostras de carne bovina pré-moída quanto nas amostras de almôndega, abaixo do recomendado pela legislação vigente no Brasil. Os valores foram notados nas duas metodologias usadas, porém os resultados obtidos com o método descrito pela Instrução Normativa 20, de 21 de julho de 1999 (BRASIL, 1999) apresentaram maior quantidade de médias com valor abaixo de 5,8 que é considerado o mínimo pela Portaria ํㅜ 1, de 7 de outubro de 1981 (BRASIL, 1981).

Esses valores de $\mathrm{pH}$ abaixo da recomendação também foram relatados por Oliveira et al. (2017) ao pesquisar o pH de carne moída em açougues de Bom Jesus-PI, usando a metodologia descrita pelo Instituto Adolfo Lutz. O valor médio de $\mathrm{pH}$ encontrado foi de 5,68, sendo que das 60 amostras coletadas para análise, 50 $(83,34 \%)$ apresentaram valor abaixo de 5,8 .

Valores dentro do limite aceito $(5,8-6,4)$ pela Portaria no 1 , de 7 de outubro de 1981 (BRASIL, 1981), foram encontrados em um trabalho realizado por Silva Júnior et al. (2018) que analisaram características microbiológicas de carne moída de supermercados em Macapá-AP. Todas as 30 amostras de carne moída bovina coletadas para análise usando a metodologia descrita pelo Instituto Adolfo Lutz, apresentaram valor de pH entre 5,8 a 6,0. Já Silva et al. (2016), também utilizando a metodologia do Instituto Adolfo Lutz ao analisarem três amostras de carne moída de um supermercado de grande porte, 3 amostras de um açougue e 3 amostras de uma feira livre na zona sul de Manaus, obtiveram valores de pH entre 5,62 e 5,93 para as amostras do supermercado, 5,93 e 5,99 para as amostras do açougue e 6,0 e 6,2 para as amostras da feira livre.

Mesquita et al. (2014) ao analisarem características físico-químicas de carne in natura de bovino de um Restaurante Universitário no Rio Grande do Sul, de 30 amostras analisadas somente $4(13,3 \%)$ foram consideradas boas para consumo (pH 5,8-6,4), sendo que $23(76,7 \%)$ apresentaram valor de $\mathrm{pH}$ abaixo de 5,8, e 3 (10\%) acima de 6,4. Em contrapartida, utilizando métodos para mensuração diferente do utilizado nesse trabalho, Conceição e Gonçalves (2009) não obtiveram resultados menores que 5,8 em uma pesquisa realizada nas cidades de Niterói e Rio de Janeiro coletando 20 amostras de carne moída bovina em dois lotes comercializadas por vários supermercados e observaram valores de $\mathrm{pH}$ entre $6,5 \mathrm{e}$ 7.

Após a comparação entre os métodos utilizados para mensuração do $\mathrm{pH}$ de almôndegas e carnes bovinas pré-moídas, pode-se dizer que o método de mensuração do $\mathrm{pH}$ escolhido pode ser um dos fatores que influenciaram o aparecimento de valores menores que o preconizado pela legislação brasileira; além disso, a metodologia descrita pela Instrução Normativa 20, de 21 de julho de 1999 (BRASIL, 1999) que é considerada oficial pelo MAPA é a mais adequada para tal análise pois apresenta resultados menores, que levam a menor condenação de amostras, se comparado a metodologia do Instituto Adolfo Lutz.

\section{Provas da Filtração e da cocção para carnes pré-moídas}

No quadro 1 estão apresentados os resultados da prova de filtração e da cocção realizadas nas amostras de carne pré-moída bovina. 
QUADRO 1. Resultados das provas de Filtração e Cocção realizadas com as amostras de carne pré-moída bovina.

\begin{tabular}{ccl}
\hline Amostra & Prova da Filtração (min) & Prova da Cocção \\
\hline $\mathbf{1}$ & $4^{\prime}$ & Característico \\
$\mathbf{2}$ & $5^{\prime}$ & Característico \\
$\mathbf{3}$ & $4^{\prime} 30^{\prime \prime}$ & Característico \\
$\mathbf{4}$ & $3^{\prime} 35^{\prime}$ & Característico \\
$\mathbf{5}$ & $3^{\prime} 40^{\prime}$ & Característico \\
\hline
\end{tabular}

As cinco amostras de carne pré-moída bovina obtidas, após serem submetidas à prova da filtração, apresentaram valores menores ou igual a 5 minutos, classificando-as como boas para consumo, segundo a Portaria ํㅡ 1 de 7 de outubro de 1981 (BRASIL, 1981). Oliveira et al. (2017) ao realizarem a prova de filtração em 60 amostras de carne moída, obtiveram o resultado de 46 amostras $(76,66 \%)$ impróprias para consumo; 10 amostras $(16,66 \%)$ de média conservação e quatro amostras $(6,66 \%)$ estavam aptas ao consumo. Já no estudo de Mesquita et al. (2014), ao analisarem carne bovina in natura em um restaurante universitário de uma Instituição Federal de Ensino Superior, somente cinco amostras (16,7\%) mostraram-se aptas para consumo. Doze amostras (40,0\%) apresentaram média conservação e 13 amostras (43,3\%) eram impróprias para consumo.

A prova da cocção foi realizada apenas com as amostras de carne pré-móida bovina pois a presença de tempero na almôndega impede a identificação de odores alterados. As cinco amostras apresentaram odor característico de carne in natura como resultado. Esse resultado concorda com o encontrado por Oliveira et al., (2016) que também classificaram $100 \%$ de suas amostras $(n=60)$ com odor e textura características da carne in natura.

Já Raghiante et al. (2018) ao avaliarem a qualidade físico-química de 15 amostras de carnes ( 5 bovinas, 5 suínas e 5 de aves) armazenadas em uma Unidade de Alimentação e Nutrição de uma universidade, constataram que duas $(13,33 \%)$ das cinco amostras de carne bovina apresentaram odor amoniacal e textura alterada. Ordõnez (2005) ressalta que, a carne in natura é caracterizada por aroma leve e a prova de cocção tem a finalidade de ressaltá-lo, além disso compostos voláteis e não-voláteis são responsáveis pelas diferentes sensações de odor.

\section{Pesquisa de sulfitos}

Todas as amostras de almôndegas e carnes pré-moídas bovina foram submetidas à prova para sulfito com verde de malaquita descrita pelo Instituto Adolfo Lutz (IAL, 2008). As amostras de carne pré-moída bovina analisadas apresentaram resultado negativo quanto à presença desta substância, demonstrando que os poucos estabelecimentos que ainda comercializam esse produto não o fraudaram com sulfito de sódio na tentativa de mascarar as características de frescor da mesma.

Esse resultado confere com trabalhos realizados em outras regiões do país. Fernandes et al. (2014) ao analisarem 32 amostras de carne moída de mercados e supermercados de Recife, não encontraram presença de sulfito de 
sódio. Costa e Tamati (2018) que relataram resultados negativos para a presença de sulfito nas 8 amostras de carne moída bovina colhidas em dois supermercados no estado do Paraná. Entretanto, em um estudo realizado por lammarino et al. (2017) foram analisados 669 produtos cárneos em um laboratório italiano entre 2013 a 2015, para averiguar a presença de sulfito. Destes, 43 (6,4\%) amostras foram positivas no teste de triagem.

Com relação às amostras de almôndegas, adquiridas nas cinco regiões da cidade de Uberlândia, verificou-se que seis amostras, que corresponde a $15 \%$ do total das 40 amostras apresentavam adição de sulfito. A região sul apresentou a maior taxa de resultados positivos do município; das oito amostras coletadas nessa região, em três foi verificada a adição de sulfito de sódio. Na região oeste e na região leste também foram encontradas almôndegas com adição de sulfito; a primeira revelou duas amostras positivas e a segunda apresentou apenas uma. Amostras procedentes da região central e a região norte não apresentaram presença de sulfito. A figura 6 representa graficamente o resultado da pesquisa de sulfito de sódio com verde malaquita; mostrando a quantidade de amostras negativas e positivas da região.

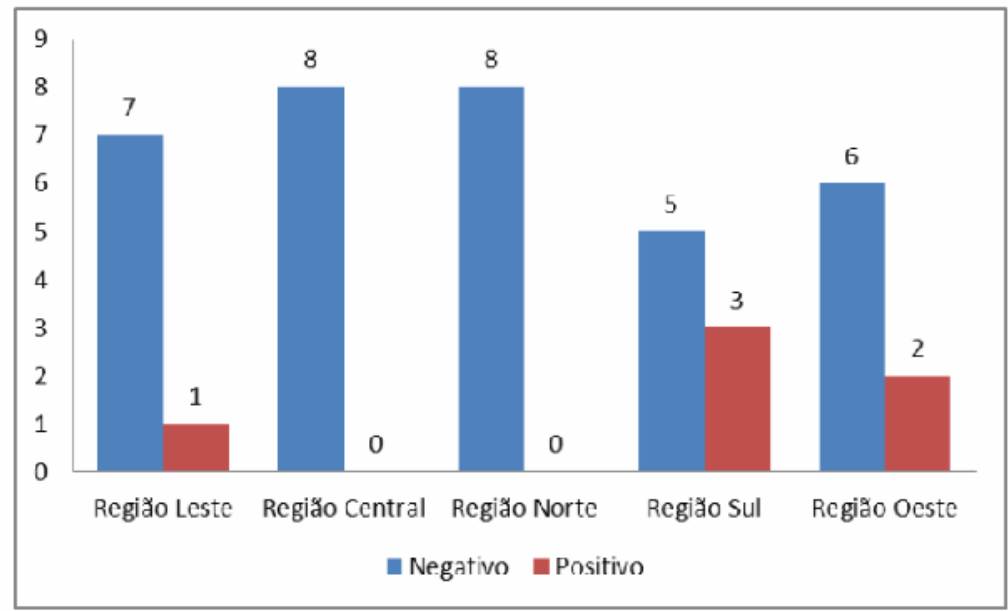

FIGURA 6. Resultados da presença (vermelho) ou ausência (azul) de sulfito de sódio em amostras de almôndega representada por regiões.

A ingestão de sulfitos tem sido associada à reações adversas sendo as mais frequentes reações alérgicas, crise asmática, ocasionalmente urticária (urticária) e algumas raras vezes anafilaxia (BAN et al., 2014; KORIĆANAC et al., 2017). Por isso a presença de tal substância em alimentos como almôndegas e carne moída, que não deveriam conter sulfito preocupa; alimentos que são de fácil acesso econômico e que podem ser ingeridos, inclusive em grandes quantidades, por pessoas sensíveis ao composto.

\section{CONCLUSÕES}

A partir dos resultados do presente trabalho, foi possível concluir que existem estabelecimentos em Uberlândia- MG que adicionam sulfito de sódio a almôndegas bovinas, o que as tornam inseguras para o consumo humano, apesar do $\mathrm{pH}$ ter valores admitidos como adequados para o consumo humano. Além disso, a falta de dados para comparar o resultado obtido no presente estudo com os de outros autores indica que as pesquisas a respeito da qualidade do produto ainda não foram completamente exploradas. 
Os métodos para avaliação de $\mathrm{pH}$ demonstram diferenças entre si e podem influenciar na classificação da carne em relação a esse fator. A metodologia descrita pela Instrução Normativa 20/1999 que é considerada oficial pelo MAPA apresenta-se como a mais adequada para essa mensuração pois condena um número menor de produtos e menor possibilidade de dar resultado falso-positivo com relação a deterioração da carne.

\section{REFERÊNCIAS}

BAN, G. Y.; KIM, M., YOO; H. S.; YE, Y. M.; PARK, H. S. Letter to the Editor: Two Major Phenotypes of Sulfite Hypersensitivity: Asthma and Urticaria. Yonsei Medical Journal, v. 55, n. 2, p. 542-544, 2014.

BRASIL. Ministério da Agricultura, Pecuária e Abastecimento. Secretaria de Defesa Agropecuária. Instrução Normativa no 20 de 21 de julho de 1999. Oficializa os Métodos Analíticos Físico-Químicos, para Controle de Produtos Cárneos e seus Ingredientes - Sal e Salmoura. Diário Oficial da União, Brasília - DF, 27 de julho de 1999, Seção 1, Página 10.

BRASIL. Ministério da Agricultura, Pecuária e Abastecimento. Secretaria Nacional de Defesa Agropecuária. Instrução Normativa no 20, de 31 de julho de 2000. Aprova os Regulamentos Técnicos de Identidade e qualidade de Almôndega, de Apresuntado, de Fiambre, de Hamburguer, de Kibe, de Presunto Cozido e de Presunto. Diário Oficial da União, Brasília - DF, 03 de agosto de 2000, Seção 1, Página 7

BRASIL. Ministério da Agricultura e Abastecimento. Instrução Normativa nำ3 de 21 de novembro de 2003. Regulamentos Técnicos de Identidade e Qualidade de Carne Bovina em Conserva (Corned Beef) e Carne Moída de Bovino. Diário Oficial da União - DF, 24 de novembro de 2003, Seção 1, Página 29

BRASIL. Ministério da Saúde. Agência Nacional de Vigilância Sanitária. Portaria n-540, de 27 de outubro de 1997. Aprova o Regulamento Técnico: Aditivos Alimentares - definições, classificação e emprego. Diário Oficial da União - DF, 28 de outubro de 1997.

BRASIL. Ministério da Saúde. Agência Nacional de Vigilância Sanitária. Portaria n-1004, de 11 de dezembro de 1998. Aprova o Regulamento técnico: atribuição de função de aditivos, aditivos e seus limites máximo de uso para a categoria 8 - Carne e Produtos Cárneos, constante do anexo desta Portaria. Diário Oficial da União DF, 14 de dezembro de 1998.

BRASIL. Ministério da Agricultura. Secretaria Nacional de Defesa Agropecuária. Laboratório Nacional de Referência Animal (LANARA). Portaria $n^{\circ}$ 01, de 07 de outubro de 1981. Métodos Analíticos Oficiais para Controle de Produtos de Origem Animal e seus Ingredientes: métodos físicos e químicos. Diário Oficial da União, Brasília - DF, 13 de outubro de 1981.

BRIDI, A. A. Consumo de carne bovina e saúde humana: convergências e divergências. In: OLIVEIRA, R. L.; BARBOSA, M. A. A. F. Bovinocultura de Corte: desafios e tecnologias. 2. ed. Salvador: EDUFBA, 2014. Disponível em: $<$ http://www.uel.br/grupo- 
pesquisa/gpac/pages/arquivos/consumo\%20de\%20carne\%20revisado\%2011\%20livro \%20ronaldo.pdf>. Acesso em: 01 abril, 2019.

CONCEIÇÃO, F. V. E.; GONÇALVES, E. C. B. A. Qualidade físico-química de mortadelas e carnes moídas e conhecimento dos consumidores na conservação destes produtos. Ciência e Tecnologia de Alimentos, Campinas, v. 29, n. 2, p. 283-290, 2009. Disponível em: <http://www.scielo.br/pdf/cta/v29n2/07.pdf> DOI: 10.1590/S0101- 20612009000200007. Acesso em: 04 abril, 2019.

COSTA, L. C.; TANAMATI, A. Avaliação higiênico-sanitária e físico-química de carne in natura comercializada em Campo Mourão-PR. REVISTA UNINGÁ REVIEW, v. 33, n. 1, p. 55-65, 2018. Disponível em: <http://revista.uninga.br/index.php/uningareviews/article/view/2067>. Acesso em: 06 abr. 2019.

CRUZ, B. C. C.; SANTOS, C. L.; AZEVEDO, J. A. G.; SILVA, D. A. Avaliação e composição centesimal e as características físico-químicas da carne de ovinos. PUBVET, v. 10, p. 111-189, 2015. Disponível em: <http://www.pubvet.com.br/uploads/49456167acc43bd17d31ea808fe99a11.pdf.> Acesso em 05 de abril, 2019. DOI: 10.22256/pubvet.v10n2.147-162

FELLOWS, P. J. Parte I Princípios básicos. Capítulo 1 Propriedades dos alimentos e princípios de processamento. In: Tecnologia do Processamento de Alimentos: Princípios e Prática. Artmed Editora, 4 Ed., p 26-161, 2018.

FERNANDES, M. F. T. S.; CAVALCANTI, E. F. T. S. F.; SILVA, J. G.; ALBUQUERQUE, P. P. F.; MOURA, A. P. B. L. Pesquisa de sulfito de sódio em amostras de carne moída comercializadas na cidade do Recife, Pernambuco, Brasil. Brazilian Journal of Veterinary Medicine, v. 36, n. 1, p. 42-44, 2014.

GOUVEIA, A. I.; LOPES, L.; CORREIA, T. Queilite de Contacto alérgica a aditivos alimentares. Revista da Sociedade Portuguesa de Dermatologia e Venereologia, v. $74, \quad$ n. 2, p. 191-193, 2016. Disponível em: <https://revista.spdv.com.pt/index.php/spdv/article/view/557/409>. Acesso em: 02 abril 2019. DOI: http://dx.doi.org/10.29021/spdv.74.2.557.

IAMMARINO, M.; IENTILE, A. R.; DI TARANTO, A. (2017) Sulphur dioxide in meat products: 3-year control results of an accredited Italian laboratory, Food Additives \& Contaminants: Part B, v. 10, n. 2, p. 99-104, 2017. Disponível em: https://www.tandfonline.com/doi/abs/10.1080/19393210.2017.1280539?journalCode =tfab20. DOI: $\underline{10.1080 / 19393210.2017 .1280539}$

INSTITUTO ADOLFO LUTZ. Métodos físico químicos para análise de alimentos, 4 ed., São Paulo, 2008.2 Disponível em: <http://www.ial.sp.gov.br/resources/editorinplace/ial/2016_3_19/analisedealimentosia I_2008.pdf>. Acesso em 01 abril, 2019.

KENDIGELEN, P.; SUCU, A.; KAYA, G. Anaphylaxis after administration of amikacin containing sodium metabisulfite in a premature newborn. Archivos argentinos de pediatria, v. 114, n. 3, p. e195-8, 2016. Disponível em: < 
https://www.sap.org.ar/docs/publicaciones/archivosarg/2016/v114n3a26e.pdf>. Acesso em 01 abril, 2019. DOI:10.5546 / aap.2016.eng.e195

KORICANAC, V.; VRANIC, D.; TRBOVIC, D.; PETRONIJEVIC, R.; PARUNOVIC, N. Presence of sulphites in different types of partly processed meat products prepared for grilling. In: IOP Conference Series: Earth and Environmental Science. 2017. p. 012067.

MESQUITA, M. O.; VALENTE, T. P.; ZIMMERMANN, A.; FRIES, L. L. M.; TERRA, N. N. Qualidade físico-químico da carne bovina in natura aprovada na recepção de restaurante industrial. Revista Vigilância em Debate, v. 2, n. 3, p.103-108, 2014. DOI: $10.3395 /$ vd.v2i3.147.

NASCIMENTO, M. V. D., GUEDES, A. T. L., SILVA, H. A., DOS SANTOS, V. E. P., FRANÇA PAZ, M. C. Avaliação da Qualidade Microbiológica da carne moída fresca comercializada no Mercado Central em Campina Grande-PB. Revista Saúde \& Ciência Online, v. 3, n. 1, p. 56-68, 2014.

OLIVEIRA, M. S.; SOUSA, V. C.; PINTO, O. C.; NUNES, G. S.; NATYLANE, E. F.; MACHADO, F. C. F.; JÚNIOR, A. A. N. M. Qualidade físico-química e microbiológica da carne moída de bovino em açougues. REDVET. Revista Electrónica de Veterinaria, v. 18, n. 12, p. 1-13, 2017.

ORDÓÑEZ, J. A. Tecnologia de Alimentos-Alimentos de Origem Animal. Tradução de Fátima Murad. Porto Alegre: Artmed, 6 ed., v. 2, 279 p, 2005.

PRICE, J. F.; SCHWEIGERT, B. S. Ciencia de la carne y de los productos carnicos. 2 ed. Zaragoza: Acribia, 1994. 592p.

RAGHIANTE, F.; SANTOS, E. A.; MARTINS, O. A. Avaliação da qualidade de carnes armazenadas em uma Unidade de Alimentação e Nutrição Institucional. Revista Brasileira de Higiene e Sanidade Animal, v.12, n.1, p. 1-10, 2018. Disponível em:

$<$ http://www.higieneanimal.ufc.br/seer/index.php/higieneanimal/article/viewFile/422/2 286>. Acesso em 04 abril, 2019.

SILVA-JÚNIOR, A. C., DO NASCIMENTO, J. F., TOSTES, E. D. S. L., \& DA SILVA, A. D. S. S. Análises microbiológicas de carne bovina moída comercializada em supermercados. PUBVET, v. 12, p. 131, 2018.

SILVA, C.; MONTEIRO, M.L.G.; RIBEIRO, R.O.R.; GUIMARÃES, C.F.M.; MANO, S.B.; SILVA, J. S.; FURTADO, S. C. Análise físico-química da carne moída comercializada na zona sul de Manaus-AM. Revista Cientifica da Fametro, v. 1, n. 1, p. 11, 2016.

VALLY, H.; MISSO, N. L.; MADAN, V. Clinical effects of sulphites additives. Clinical and Experimental Allergy, v. 39, p 1643-1651, 2009. Disponível em: https://onlinelibrary.wiley.com/doi/full/10.1111/j.1365-2222.2009.03362.x

DOI:10.1111 / j.1365-2222.2009.03362.x 